\title{
Socio-Demographic Determinants of Child Sex Ratio and Its Regional Variation in India
}

\author{
Dr. M. R. Singariya \\ Lecturer in Economics, Government College Jaitaran (Raj.)
}

\begin{abstract}
Rapid decline in child sex ratio (CSR) is a serious problem with severe socio-economic, demographic and cultural implication. Using Ordinary Least Square (OLS) and Quantile Regression estimates for thirty five states and union territories of India, the paper tries to examine the determinants of child sex ratio. The results show that the female literacy rate has significant positive while male literacy and percentage share of the urban population have a significant negative association with child sex ratio in India. Decadal population growth rate has a significant positive association with rural child sex ratios but insignificant negative associated with urban child sex ratio. The revealing quantile regression estimates suggest that female literacy and decadal population growth rate have significant positive, while male literacy, urban population and infant mortality rate have a significant negative association at 0.10 quantile, where the problem is severe. The variables like urban population and infant mortality rate have significant lowest negative association at the upper tail $(0.90$ quantile) of the child sex ratio. Furthermore, the paper also highlighted regional variations through regional dummy variables. Coefficients of child sex ratio with regional dummy variables show that north - west region has highest negative and southern region has a highest positive influence on juvenile sex ratio of India. Thus strengthening of female education and reduction in higher usage of sex determination tests and infant mortality rate is an utmost need for balancing child sex ratio in north and northwest region of India.
\end{abstract}

Keywords: Child sex ratio, OLS, male and female literacy, regional variations, India.

\section{Introduction}

India is a country of striking demographic diversity. It exhibits a relatively high but declining fertility and uneven economic development with marked regional disparities by social group, age group and levels of prosperity (Agnihotri, 1995; Dyson \& Moore, 1983). The Northern and Southern states exhibit considerable differences. While the north has lower levels of literacy and relatively higher level of agricultural development, the south generally exhibits higher literacy levels and better health facilities. India is one of the few countries in the world where males outnumber females. The sex ratio of the Indian population has shown a secular declining trend except some marginal increases in the censuses of 1951, 1981, 2001 and 2011. The sex ratio in 2011 was 940, seven points higher than the sex ratio of 933 recorded in 2001.

It has been widely recognized that sex ratio (number of females per thousand males) is an important indicator to study the various aspects of population, especially human development. In India, seven point increase shown by the 2011 census in overall sex ratio is applauded at several forums. However, decline in the juvenile sex ratio has been a serious concern among social think tanks in the country. Decline in the juvenile sex ratio has been seen solely in the context of sex selective abortion or female infanticide in India. Further, the sex ratio for children will be a deciding factor for tomorrow's overall sex ratio in the population, and therefore today's improvement in overall sex ratio does not guarantee to its sustainability in the positive direction. Moreover, researchers advocate that the women's relative position in any societies taking overall sex ratio of the population ignoring the fact that sex ratio is influenced by the current and past vital rates of that population (Paula et. al, 2000).

\section{Review of Literature}

Much of the literature in Indian sex ratios has focused on a North-South dichotomy in the sex ratios (Dyson \& Moore 1983, Agarwal 1986 and Sen 2003). This literature has argued that the northern and western regions of the country not only have more rigid norms of female seclusion, particularly related to participation in economic activities outside the home, but also have marriage customs such as large dowry payments that make girls an economic burden on the family. In contrast, women in the South and East enjoy greater autonomy and higher social status within the family. These cultural differences manifest themselves in the form of lower sex ratios at birth in the northern and western states than in the southern and eastern states.

Sex selective abortions and son preference attitude are also identified as determinants of declining sex ratio in certain studies related to Asian countries (D'Souza \& Chen 1980; Park \& Cho 1995; Kynch \& Sen 1983 and Das \& Gupta 1987). These studies attributed excess female mortality to a general preference for sons, which 
in turn traced it to either higher expected return to the labour of male over female children or anticipated old-age support from sons within the patrilineal kinship system (Berik \& Bilginsoy 2000). Visariya (1969) also claimed that 'excess female literacy' is the basic reason for the declining sex ratio and excess female mortality in turn is the result of female infanticide, female foeticide, neglect of females and maternal mortality. Barbara Diane Miller (1989) examined the changes in the regional patterns of juvenile sex ratio in rural India from the censuses of 1961 and 1971. It was found that while sex differentials in childhood mortality were substantial and widely distributed in India at the time of the 1961 Census, they were even more so by the time of the 1971 census. Yet another recent study of spatial variations in sex ratio in the context of India is Klasen and Claudia (2003), where they found labour force participation rate and literacy rate of women significant in lessening sex ratio; while increasing recourse to sex selective abortions worsen it. Chakraborty \& Sinha (2008) examined the determinants of declining child sex ratio in India; the study uses fixed effects model for four decennial census data (19712001) across fifteen major states found that the child sex ratio is inversely related to the spatial socio-economic characteristics, in particular, female literacy rate and female economic activity rate; with relatively higher elasticity coefficients for urban India.

\section{Trends}

The overall sex ratio is determined by several factors such as age-specific differences in mortality and migration rates across males and females. For this reason, sex ratios for infants and children are better measures of the differential treatment of males and females in a society. Although the overall sex ratio in India has improved to 940 in census 2011 by seven points compared to that of 2001 . The only reason for that is that life expectancy of women has gone up. This means, that there are older women in the population that there were 10 years ago but the main concern remains the poor child sex ratio (TNN Apr 01, 2011). These trends probably result from three factors: sex - selective abortions (Feticide) based on prenatal ultrasounds, excess female (relative to male) infant and child mortality, and differential contraceptive use depending upon the sex composition of existing children. All three in reflect a strong cultural preference for sons over daughters (Deolalikar et al. 2009).

Figure 1 shows the percent change in child sex ratio in thirty five states and union territories of India during the last decade. There are only eight states and union territories, where the child sex ratio has been marginally improved rest of all states and union territories have shown a declining trend in the last decade. The highest percentage decline was observed in Jammu \& Kashmir followed by Dadra \& Nagar Haveli, Lakshadweep, Maharashtra, Rajasthan, Uttarakhand, Manipur, Jharkhand and Madhya Pradesh. Sixteen states and union territories have been shown a higher decline than the national average while nineteen states and union territories have been observed above than national average.

\section{Data \& Methodology}

The present paper is primarily based on secondary data collected from Census of India, 2011 and Sample Registration System 2009. Table 1 shows the descriptive statistics of selected variables for thirty five states and union territories of India for census year 2011. The child sex ratio is ranging between 830 to 964 in thirty five states and Union territories of India. On average one third of total females are illiterate in India and about $33 \%$ of the total population are living in urban areas of India. Here, the well known difference emerged in decadal population growth rate from $5 \%$ to $25 \%$, suggesting that awareness about population control is not similar in all around India.

As statistical methods we used ordinary least square method and heteroscedasticity corrected model separately for total rural and urban. As it is well known, the quantile regression technique is a means of allowing estimated marginal effects to differ at different points of the conditional distribution of the dependent variable. Quantile regressions were initially developed as a robust regression technique that would allow for estimation where the typical assumption of normality of the error term might not be strictly satisfied (Koenker \& Bassett 1978). However, they are now used extensively to analyze the relationship between dependent and independent variables over the entire distribution of the dependent variable-not just as the conditional mean (Buchinsky \& Eide 1994). Finally, four regional dummy variables were included in addition to these variables in the analysis to reveal whether there is any regional impact on the child sex ratio. One's were given to the state by concerning the region, and zeros were assigned to all other states of India.

Appropriate diagnostic tests have also been performed in checking accuracy of the models. SPSS vs. 17 and gretl vs. 1.9.5 Software was used for database, figure constructions and regression analysis. Based on the findings, some policy recommendations have also been suggested for balancing the juvenile sex ratio in states and union territories of India. 


\section{Results And Discussion}

The results show (Table 2) that female literacy rate has significant positive while male literacy and percentage share of the urban population have a significant negative association with child sex ratio in India. Decadal population growth rate has a significant positive association with rural child sex ratios but insignificant negative associated with urban child sex ratio. Percentage of urban population (PSUP) has a statistical significant negative association with child sex ratio in both OLS and heteroscedasticity corrected model. It reveals the fact that due to easy availability and use of sex determination tests in city's child sex ratio is declining especially in urban areas of India. The Infant mortality rate has been observed as the negative association with child sex ratio in India. It has a significant negative association with rural child sex ratio in heteroscedasticity corrected model, suggesting that the female infant mortality rate is higher than the male infant mortality rate. It may be due to son preference attitude in rural areas of India.

The revealing quantile regression estimates (Table 3) suggest that female literacy and decadal population growth rate have significant positive, while male literacy, urban population and infant mortality rate have a significant negative association at 0.10 quantile, where the problem is severe. The variables like urban population and infant mortality rate have significant lowest negative association at the upper tail ( 0.90 quantile) of the child sex ratio. The female literacy rate has a statistical significant positive association with the child sex ratio at all Quintiles. It also highlights that positive impact is reducing on the upper tail of child sex ratio. It is also important to reveal the fact that the male literacy rate has an insignificant negative association with a child sex ratio on upper tail, suggesting that strengthening education facilities especially for a female would empower women and reduce male dominance that would be helpful in balancing the child sex ratio.

Furthermore, the paper also highlighted regional variations through regional dummy variables. Coefficients of child sex ratio with regional dummy variables show that the north - west region has highest negative and southern region has a highest positive influence on juvenile sex ratio of India, while north east and central southern dummy have positive and insignificant association child sex ratio in India. Policies adopted in South India especially in Kerala would be more effective for to measure the declining child sex ratio in India.

\section{Conclusions}

In this paper we have focused on socio-demographic variables like male and female literacy rate, decadal population growth rate, percentage share of urban population and infant mortality rate as independent variables and child sex ratio as dependent variables in thirty five states and UT's of India for the census year 2011 through OLS, Quintile Regression estimates.

The female literacy rate has significant positive while male literacy and percentage share of the urban population have a significant negative association with child sex ratio in India.

Percentage of urban population (PSUP) has a statistical significant negative association with child sex ratio in both OLS and heteroscedasticity corrected model.

Percentage of urban population (PSUP) has a statistical significant negative association with child sex ratio in both OLS and heteroscedasticity corrected model. It reveals the fact that due to easy availability and use of sex determination tests in city's child sex ratio is declining especially in urban areas of India.

The revealing quantile regression estimates (Table 3) suggest that female literacy and decadal population growth rate have significant positive, while male literacy, urban population and infant mortality rate have a significant negative association at 0.10 quantile, where the problem is severe.

The paper also highlighted regional variations through regional dummy variables. Coefficients of child sex ratio with regional dummy variables show that the north - west region has highest negative and southern region has a highest positive influence on juvenile sex ratio of India, while north east and central southern dummy have positive and insignificant association child sex ratio in India. Policies adopted in South India especially in Kerala would be more effective for to measure the declining child sex ratio in India.

\section{References}

[1]. Agnihotri, S.B. (200), "Sex Ratio Patterns in Indian Population: A Fresh Exploration", Sage Publications, New Delhi.

[2]. Buchinsky \& Eide (1994),"Changes in the U. S. Wage Structure 1963-1987: Application of Quantile Regression" Econometrica 62:405-27-58.

[3]. Census of India (2011), "State wise: Population Census 2011 India details and analysis", http:www.census2011.co.in/states.php, accessed on $7 / 12 / 2012$.

[4]. Clark, A. (1983), "Limitations on Female Life Chances in Rural Central Gujarat", The Indian Economic and Social History Review, Vol. 20, No. 1, pp, 1-25

[5]. Croll, Elisabeth (2000), "Endangered Daughters: Discrimination and Development in Asia", Routledge, New York.

[6]. Dyson, T and Moore (1983), "On Kinship Structure, Female Autonomy and Demographic Behaviour in India" Population and Development Review 9:35-60.

[7]. Edlund, L (1999), "Son Preference, Sex Ratios and Marriage Patterns", Journal of Political Economy, 107:1275-304.

[8]. Hatti, Neelambar and Ohlsson, Rolf (1984), “Age at Marriage in India 1960-79”, Demography India, No.2.

[9]. Hatti, Neelanber, T.V.Sekhar, M Larsen (2004), "Lives at Risk: Declining Child Sex Ratio in India", Lund papers in Economic History, Number 93. 
[10]. Koenker, R. \& Bassett, G. (1978), "Regression Quantiles” Econometrica 46:33-50.

[11]. Miller, Barbara D (1981), "The Endangered Sex: Neglect of Female Children in Rural North India" Ithaca: Cornell University Press.

[12]. Registrar General of India (2009), Sample Registration System, Statistical Report.

[13]. Sekher, T.V, K.N.M. Raju and M. N. Sivakumar (2001), "Fertiltiy Transition in Karnataka: Levels, Trends and Implications", Economic and Political Weekly, 36 (51): 4742-52.

[14]. Singariya, M.R. (2012), "Determinants of Declining Child Sex Ratio in Rajasthan" Journal of Economics and Sustainable Development, IISTE, Vol3, No1, PP 9-19. Online: www.iiste.org

[15]. Visariya, P. (1971), "The Sex Ratio of Population of India”, Census of India 1961. Monograph No. 10. Manager of Publications, Delhi.

Figure 1: Percent Change in Child Sex Ratio in India, 2001-2011

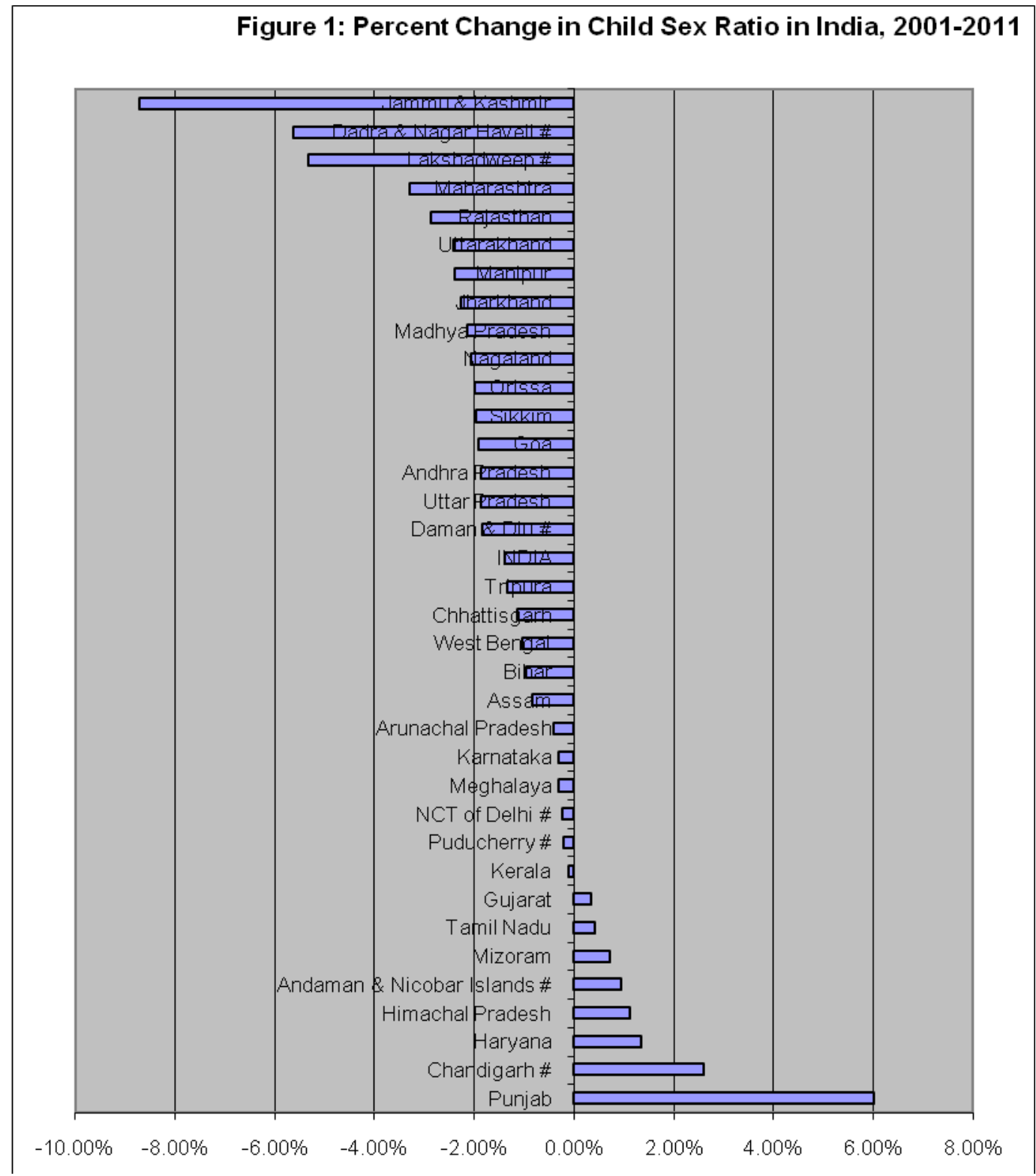

\begin{tabular}{|c|c|c|c|c|c|c|}
\hline S.N. & Variable & $\mathrm{N}$ & Minimum & Maximum & Mean & Std. Deviation \\
\hline 1 & CSR & 21 & 830.00 & 964.00 & 910.8571 & 40.35008 \\
\hline 2 & DPGR & 21 & 4.86 & 25.07 & 17.5871 & 4.84836 \\
\hline 3 & LR & 21 & 63.82 & 93.91 & 75.4829 & 7.42749 \\
\hline 4 & LRM & 21 & 73.39 & 96.02 & 83.3833 & 5.68020 \\
\hline 5 & LRF & 21 & 52.66 & 91.98 & 67.1014 & 9.72946 \\
\hline 6 & PSUP & 21 & 10.04 & 97.50 & 32.8410 & 18.65353 \\
\hline 7 & IMR & 21 & 11.00 & 67.00 & 45.0476 & 14.63378 \\
\hline
\end{tabular}


Socio-Demographic Determinants of Child Sex Ratio and Its Regional Variation in India

\begin{tabular}{|c|c|c|c|c|c|c|}
\hline - & \multicolumn{3}{|c|}{ Ordinary Least Square Model } & \multicolumn{3}{|c|}{ Heteroscedasticity Corrected Model } \\
\hline Dependent & CSR (Total) & CSR (Rural) & CSR (Urban) & CSR (Total) & CSR (Rural) & CSR (Urban) \\
\hline Indepen. & Coefficient & Coefficient & Coefficient & Coefficient & Coefficient & Coefficient \\
\hline Cons. & $\begin{array}{l}1072.44 \\
(8.57)^{* * *}\end{array}$ & $\begin{array}{l}1072.80 \\
(9.45)^{* * *}\end{array}$ & $\begin{array}{l}826.74 \\
(3.45)^{* * *}\end{array}$ & $\begin{array}{l}1114.5 \\
(15.82)^{* * *}\end{array}$ & $\begin{array}{l}1044.79 \\
(28.3)^{* * *}\end{array}$ & $\begin{array}{l}765.515 \\
(5.54) * * *\end{array}$ \\
\hline DPGR & $\begin{array}{l}0.726 \\
(1.257)\end{array}$ & $\begin{array}{l}1.054 \\
(3.08)^{* * *}\end{array}$ & $\begin{array}{l}-0.107 \\
-0.81)\end{array}$ & $\begin{array}{l}0.479 \\
(1.307)\end{array}$ & $\begin{array}{l}1.079 \\
(7.41)^{* * *}\end{array}$ & $\begin{array}{l}-0.161 \\
(-2.65) * *\end{array}$ \\
\hline PSUP & $\begin{array}{l}-1.018 \\
(-2.77)^{* * * *}\end{array}$ & & & $\begin{array}{l}-0.821 \\
(-3.135)^{* * *}\end{array}$ & & \\
\hline LRM & $\begin{array}{l}-4.194 \\
(-2.07) * *\end{array}$ & $\begin{array}{l}-3.335 \\
(-1.9)^{*}\end{array}$ & $\begin{array}{l}-2.78 \\
(-0.689)\end{array}$ & $\begin{array}{l}-4.649 \\
(-3.67) * * *\end{array}$ & $\begin{array}{l}-2.99 \\
(-4.63) * * *\end{array}$ & $\begin{array}{l}-2.822 \\
(-1.186)\end{array}$ \\
\hline LRF & $\begin{array}{l}3.605 \\
(2.76)^{* * *}\end{array}$ & $\begin{array}{l}2.379 \\
(2.08)^{* *}\end{array}$ & $\begin{array}{l}4.431 \\
(1.96)^{*}\end{array}$ & $\begin{array}{l}3.522 \\
(3.97)^{* * *}\end{array}$ & $\begin{array}{l}2.32 \\
(5.95)^{* * *}\end{array}$ & $\begin{array}{l}5.176 \\
(4.22) * * *\end{array}$ \\
\hline IMR & $\begin{array}{l}-0.647 \\
(-1.145)\end{array}$ & $\begin{array}{l}-0.832 \\
(-1.50)\end{array}$ & $\begin{array}{l}-0.66 \\
(0.898)\end{array}$ & $\begin{array}{l}-0.616 \\
(-1.73)^{*}\end{array}$ & $\begin{array}{l}-0.725 \\
(-3.82) * * *\end{array}$ & $\begin{array}{l}-0.36 \\
(-0.748)\end{array}$ \\
\hline $\mathrm{R}^{2}$ & .366 & .356 & .312 & .507 & .849 & .854 \\
\hline Adj. $\mathrm{R}^{2}$ & .256 & .271 & .220 & .422 & .829 & .835 \\
\hline Obs. & 35 & 35 & 35 & 35 & 35 & 35 \\
\hline
\end{tabular}

\begin{tabular}{|l|l|l|l|l|l|}
\hline \multicolumn{2}{|l|}{ Table 3: Quantile Regression Estimates for Child Sex Ratio in India For Census 2011. } \\
\hline Quantile & 0.10 & 0.25 & 0.5 & 0.75 & 0.90 \\
\hline Cons. & 1072.6 & 1218.15 & 1110.22 & 1078.4 & 928.48 \\
& $(19.68)^{* * *}$ & $(9.112)^{* * *}$ & $(7.68)^{* * *}$ & $(9.07)^{* * *}$ & $(26.6)^{* * *}$ \\
\hline DPGR & 1.04 & 0.745 & 0.358 & 0.125 & 0.513 \\
& $(4.139)^{* * *}$ & $(1.207)$ & $(0.577)$ & $(0.228)$ & $(3.185)^{* * *}$ \\
\hline PSUP & -1.27 & -0.822 & -1.16 & -0.411 & -0.349 \\
& $(-7.95)^{* * *}$ & $(-2.097)^{* *}$ & $(-2.736)^{* *}$ & $(-1.18)$ & $(-3.414)^{* *}$ \\
\hline LRM & -6.576 & -6.04 & -3.943 & -3.557 & -0.524 \\
$(-0.927)$
\end{tabular}

\begin{tabular}{|c|c|c|c|c|c|c|c|c|}
\hline Variables & Coef. & $\mathrm{t}$ - ratio & Coef. & $\mathrm{t}$ - ratio & Coef. & t- ratio & Coef. & t- ratio \\
\hline Constant & 997.52 & $11.44 * * *$ & 1044.05 & $9.28 * * *$ & 987.05 & $6.76^{* * * *}$ & 1104.15 & $8.257 * * *$ \\
\hline DPGR & 0.238 & 0.586 & 1.1633 & $2.15 * *$ & 0.566 & 0.955 & 0.60 & 0.99 \\
\hline LRM & -2.2 & -1.528 & -4.0232 & $-2.15 * *$ & -2.65 & -1.086 & -4.747 & $-2.17 * *$ \\
\hline LRF & 2.0577 & $2.19 * *$ & 3.547 & $3.033 * * *$ & 2.69 & $1.75^{*}$ & 3.85 & $2.83^{* * *}$ \\
\hline PSUP & -0.576 & $-2.179 * *$ & -1.17 & $-3.51 * * *$ & -0.793 & $-1.907^{*}$ & -1.1019 & $-2.75 * *$ \\
\hline IMR & -0.068 & -0.17 & -0.446 & -0.88 & -0.447 & -0.764 & -0.697 & -1.22 \\
\hline DNNW & -57.25 & $-5.77 * * *$ & - & - & - & - & - & - \\
\hline DSI & - & - & 40.016 & $2.847 * * *$ & - & - & - & - \\
\hline DNE & - & - & - & - & 19.19 & 1.12 & - & - \\
\hline DCW & - & - & - & - & - & - & 11.12 & 0.712 \\
\hline $\mathrm{R}^{2}$ & .708 & & .507 & & 0.392 & & 0.376 & \\
\hline Adj. $\mathrm{R}^{2}$ & .646 & & .402 & & 0.262 & & 0.243 & \\
\hline Obs. & 35 & & 35 & & 35 & & 35 & \\
\hline
\end{tabular}

Coef. $=$ Coefficient

*** Significant at $1 \%$ level, ** significant at $5 \%$ level and $*$ Significant at $10 \%$ level. 